\title{
Telomere length differences upon keratinization and its variations in normal human epidermal keratinocytes
}

\author{
Katsuhiro Hitomi ${ }^{1,2}$ \\ ${ }^{1}$ Department of Dermatology, Yamagata University School of Medicine, Yamagata, Japan \\ ${ }^{2}$ Present Affiliation: Department of Dermatology, Saitama Medical Center, Saitama Medical University, Kawagoe, Japan \\ Email address: \\ k-hitomi@js4.so-net.ne.jp
}

To cite this article:

Katsuhiro Hitomi. Telomere Length Differences upon Keratinization and its Variations in Normal Human Epidermal Keratinocytes. Cell Biology. Vol. 2, No. 4, 2014, pp. 28-35. doi: 10.11648/j.cb.20140204.11

\begin{abstract}
Telomeres are the physical ends of chromosomes, and are cleaved with each cell division. Telomere loss results from not only incomplete DNA replication ("end replication problem"), followed by the processing of chromosome, but also exposure to various DNA damaging agents. Human epidermis is constantly replaced through replication at the basal layer, followed by upward movement and terminal differentiation at the suprabasal layer. The objective of this study was to assess differences in telomere length between basal and suprabasal keratinocytes, and variations of telomere lengths among basal cells. We investigated terminal restriction fragment (TRF) length in fractions of epidermal cells by Southern blot analysis. Time-dependent trypsin treatment to epidermis divided into basal cell rich and suprabasal cell rich fractions. In the five skin samples from various sites of the body, the mean TRF length were 5,932 \pm 470 (range 5,182-6,630) bp in basal cell rich fraction showing $21.5 \% \pm 5.8 \%$ (range 12.6-28.6\%) of keratin 10 (K10)-positivity, which is marker of keratinizing suprabasal cell, and $5,320 \pm 640$ (range 4,495-6,212) bp in suprabasal cell rich fraction showing 78.8\% $\pm 4.0 \%$ (range 72.8-83.0\%) of K10-positivity. It was calculated that K10 positive cells have 1,091 \pm 963 (range 248-2,650) bp shorter telomeres compared to K10 negative cells. In addition, fluorescence in situ hybridization (FISH) study showed that columnar groups of keratinocytes with statistically longer telomere in each nucleus than the other epidermal cells in the vicinity occupied occasionally between the tip of dermal papilla and the bottom of rete ridge. The present study showed that the keratinizing suprabasal cells have shorter telomeres compared to basal cells. FISH study showed that some groups of epidermal cells having different replicative histories among the groups of epidermal cells in the vicinity.
\end{abstract}

Keywords: Human Skin, Keratinocyte, Fluorescence in Situ Hybridization, Telomere, Terminal Restriction Fragment

\section{Introduction}

Telomeres, the physical ends of eukaryotic chromosomes, are structurally important for the stability and integrity of chromosomes [1,2]. Human telomeres contain 5 to $15 \mathrm{kbp}$ of a highly conserved sequence, (TTAGGG) $)_{\mathrm{n}}$, with the G-rich strand oriented in $5^{\prime}$ to $3^{\prime}$ direction toward the chromosome ends [3]. One characteristic of replicating cells is telomere shortening, which may trigger growth arrest and senescence [4]. Loss of telomeric DNA at the cellular level is well established and is related to replicative history and life span in somatic cells [5]. However, at the level of tissues or the entire organism, the biological role of telomere shortening is not fully understood.

Human epidermis is a continuously renewing stratified epithelium comprising a basal layer of proliferative cells and suprabasal layers of more differentiated cells that undergo terminal differentiation [6]. Basal cells divide both symmetrically and asymmetrically [7,8]. Some basal cells withdraw from the cell cycle and detach from the basement membrane. To explain the interfollicular epidermal homeostasis, three models of organization of the basal layer have been assumed by lineage tracing studies; one suggests that there is only one type of progenitor population in the basal layer and that it directly generates differentiated cells [7], and the other two are hierarchy models suggesting that to generate differentiated cells, basal cells pass through from slow-cycling and self-renewing stem cells (SCs) to actively cycling and self-renewing committed progenitor cells (CPCs) [8], or from SCs via CPCs to non-self-renewing transient amplifying cells (TACs), which undergo limited cell division and differentiate to suprabasal cells [9].

In previous studies of human keratinocytes, Southern blot 
analyses of terminal restriction fragment (TRF) showed age-dependent telomere shortening. Reduction rates of 19.8 $\mathrm{bp} /$ year were reported in the epidermis of 21 subjects aged $0-92$ years by Lindsey et al. [10], and of $75 \mathrm{bp} /$ year in the skin of seven subjects aged 73-91 years by Friedrich et al. [11]. Nakamura et al. showed that neonatal epidermal cells have telomere length of $13.2 \pm 1.0 \mathrm{kbp}$, which decreases at 36-39 bp/year [12]. Sugimoto et al. compared TRF length in epidermal cells in both sun-exposed and sun-protected areas at various ages and calculated that the mean TRF length of $8.96 \mathrm{kbp}$ in neonates decrease at a rate of $9 \mathrm{bp} / \mathrm{year}$ [13]. Krunic et al. estimated approximately $25 \mathrm{bp} /$ year in an in vitro first-passage epidermal cell culture and tissue section study [14]. In eight patients with Werner syndrome, the gradual loss of telomere size with age was found to be significantly accelerated [15], suggesting close relationships between telomere shortening and senescence.

On the other hand, transitional variations in telomere length from basal to suprabasal layers in human epidermis have not been fully evaluated. Here, we report the changes in telomere length by Southern blot analysis in fractionated basal cells and suprabasal cells. Furthermore semi-quantitative fluorescence in situ hybridization (FISH) analysis was used to compare the modulation of telomere length in basal cells and their descendant suprabasal cell groups.

\section{Materials and Methods}

\subsection{Skin Samples}

Paraformaldehyde (4\%)-fixed and paraffin-embedded sections, cryosections, isolated epidermal keratinocytes and primary cultured dermal fibroblasts were prepared from normal human skin samples obtained from seven individuals aged between 18-74 years from sites such as the forehead, abdomen, back, axilla, leg and sole of the foot, after obtaining informed consent.

\subsection{Fractionation of Epidermal Cells}

We isolated normal keratinocytes according to the method of Härle-Bachor and Boukamp [16]. Skin samples (approximately $50 \mathrm{~mm}^{2}$ ) were incubated overnight at $4^{\circ} \mathrm{C}$ in Dulbecco's modified Eagle's medium (DMEM; Dainihon Chemical Co., Osaka, Japan) containing 1,000 U/ml dispase (Godosyusei Inc., Tokyo, Japan). Epidermis was then peeled away from the dermis with forceps and floated on $0.125 \%$ trypsin $/ 0.01 \%$ EDTA solution for 2 to $18 \mathrm{~min}$ at $37^{\circ} \mathrm{C}$. By pipetting the culture medium, single cells dropped down to the medium from epidermis and we obtained cell mixtures containing different proportions of basal and suprabasal cells based on trypsinization time.

Cryosections $(6 \mu \mathrm{m})$ and trypsin-isolated keratinocytes were placed on glass slides, were fixed with cold acetone for $10 \mathrm{~min}$, and were incubated with primary mouse antibodies against keratin 10 (DE-K10, 1:30 dilution; Dako, Glostrup, Denmark) in order to identify keratinizing cells in suprabasal layers. Similarly, anti-keratin 5 (RCK 102, 1:10 dilution; Szabo-Scandic, Wien, Germany) was used to identify basal cells. Rabbit anti-mouse fluorescein isothiocyanate (FITC) secondary antibodies (Dako) were used for immunofluorescence staining. In each cell fraction, keratin 10- or 5-positive cells were counted and expressed as a percentage of total numbers of cell nuclei counterstained with 4', 6-diamidino-2-phenylindole (DAPI) in each cell mixture.

\subsection{Fibroblast Cell Culture}

Fibroblasts were separated from the dermis, and were maintained in DMEM containing $10 \%$ fetal bovine serum. Routine subcultures were obtained by disaggregating cells with $0.125 \%$ trypsin $/ 0.01 \%$ EDTA solution and re-plating at a split ratio of 1:2.

\subsection{Southern Blot Analysis of TRF Length in Trypsin-Isolated Keratinocytes}

DNA isolation and Southern blot analysis were carried out according to the method of Bryant et al. [17]. Approximately $4 \mu \mathrm{g}$ of isolated genomic DNA digested with Rsa I and Hinf I (New England Biolabs, Beverly, MA) was subjected to electrophoresis on a $0.8 \%$ agarose gel. DNA was transferred onto a nylon membrane (Magnagraph, Micron Separations Inc., Westborough, MA), and was hybridized in hybridization solution contain 5 -fold concentrated $(5 \times)$ sodium chloride sodium citrate ( $\mathrm{SSC} ; 16.6 \mathrm{mM} \mathrm{NaCl}, 16.6 \mathrm{mM} \mathrm{C}_{6} \mathrm{H}_{5} \mathrm{O}_{7} \mathrm{Na}_{3}$ ), $0.1 \%$ SDS and $100 \mu \mathrm{g} / \mathrm{ml}$ salmon sperm DNA at $60^{\circ} \mathrm{C}$ with a $(\mathrm{TTAGGG})_{4}$ probe end-labeled with $\left[{ }^{32} \mathrm{P}\right] \mathrm{ATP}$ for $16 \mathrm{~h}$. Post-hybridization washes consisted of two rinses and two subsequent 30 -min washes with agitation in $100 \mathrm{ml}$ at $60^{\circ} \mathrm{C}$ $5 \times \mathrm{SSC}$ and three $10-\mathrm{min}$ washes with agitation in $200 \mathrm{ml}$ at room temperature one-tenth diluted $(0.1 \times)$ SSC. Membranes were air-dried for $30 \mathrm{~min}$, and hybridization signals were visualized by autoradiography. The hybridization signal intensities of TRFs were plotted against TRF lengths, and the length that divided the area under the curve into two equal halves was determined using ImageJ software (http://rsbweb.nih.gov/ij/). This length was taken to be the approximate mean TRF length.

\subsection{Preparation of Digoxigenin-Labeled Telomere Probes and FISH in Normal Skin Sections}

Plasmid pTh5 containing the (TTAGGG) ${ }_{28}$ repeat [18] was used as a template to generate telomere probes with the polymerase chain reaction (PCR) DIG Probe Synthesis Kit (Boehringer Mannheim, Mannheim, Germany), in accordance with the manufacturer's protocol. Linearization with Nde I (New England Biolabs) and subsequent PCR incorporating digoxigenin-labeled dUTP produced telomere probes. Telomere probes were amplified with the primer pair 5'-GAACCAGATCTGATATCATG-3', and 5'-CCGGGTACCGAGCTCGAATT-3'. PCR amplification conditions were 40 cycles of denaturation at $95^{\circ} \mathrm{C}$ for $30 \mathrm{~s}$, annealing at $60^{\circ} \mathrm{C}$ for $30 \mathrm{~s}$ and extension at $72^{\circ} \mathrm{C}$ for $20 \mathrm{~s}$.

Skin samples fixed in $4 \%$ paraformaldehyde were 
embedded in paraffin, cut into $6-\mu \mathrm{m}$ serial sections and mounted on 3-aminopropyltriethoxysialene-coated glass microscope slides (Matsunami Glass Co., Osaka, Japan). Sections were deparaffinized, digested with $10 \mu \mathrm{g} / \mathrm{ml}$ of proteinase $\mathrm{K}$ diluted in $10 \mathrm{mM}$ Tris- $\mathrm{HCl}(\mathrm{pH} \mathrm{7.4)/1} \mathrm{mM}$ EDTA at $28^{\circ} \mathrm{C}$ for 20 min, postfixed with $4 \%$ paraformaldehyde, and incubated with $0.25 \%(\mathrm{v} / \mathrm{v})$ acetic anhydride in $0.1 \mathrm{M}$ triethanolamine $(\mathrm{pH} 8.0)$. The solution used for prehybridization and hybridization consisted of $50 \%$ formamide, 2-fold concentrated (2×) SSC, 10\% dextran sulfate, $1 \mu \mathrm{g} / \mu \mathrm{l}$ sheared salmon sperm DNA and $1 \mu \mathrm{g} / \mu \mathrm{l}$ bovine serum albumin. Slides were covered with digoxigenin-labeled telomere probes and were denatured at $75^{\circ} \mathrm{C}$ for $3 \mathrm{~min}$ on a hot plate. Prehybridization and hybridization were performed at $42^{\circ} \mathrm{C}$ for $30 \mathrm{~min}$ and overnight, respectively. Slides were washed consecutively with $50 \%$ formamide $/ 2 \times \mathrm{SSC}, 2 \times \mathrm{SSC}$ and $1 \times \mathrm{SSC}$. Hybridized probes were detected by immunofluorescence. Tissue sections were incubated at $37^{\circ} \mathrm{C}$ for $60 \mathrm{~min}$ with $1 \%$ digoxigenin-blocking reagent (Boehringer Mannheim), $0.1 \mathrm{M}$ Tris- $\mathrm{HCl}(\mathrm{pH} 7.4), 0.15 \mathrm{M} \mathrm{NaCl}$ and biotin-conjugated mouse monoclonal anti-digoxigenin IgG (CovalAb, Lyon, France). After three washes for $10 \mathrm{~min}$ each in washing buffer [0.1 M Tris- $\mathrm{HCl}$ ( $\mathrm{pH} 7.4$ ), $0.15 \mathrm{M} \mathrm{NaCl}, 0.05 \%$ SDS], slides were incubated at room temperature for $20 \mathrm{~min}$ with FITC-conjugated streptavidin (Dako), washed three times for $10 \mathrm{~min}$ in washing buffer, and mounted in antifade solution containing propidium iodide. Photographs were taken with a Nikon ECLIPSE E600 photomicroscope equipped with a B2A filter (Nikon, Tokyo, Japan).

\subsection{Semi-Quantitative Analysis of Telomere Fluorescence Signals of FISH}

Confocal microscopy (model TCS 4D; Leica, Heerbrugg, Switzerland) assessed and recorded the intensity of FITC fluorescence by optically sectioning the entire thickness of skin sections. Fluorescence intensity was determined from confocal digital images by ImageJ. Statistical analyses were performed using analysis of variance (ANOVA) significant test followed by multiple comparisons in comparison of more than two groups and Student's paired t-test between the two groups. $P$ values less than 0.05 are considered statistically significant.

\section{Results}

\subsection{Telomere Loss during Passage of Fibroblast Cell Culture}

To confirm that the fluorescence intensity of telomere signals in interphase nuclei on FISH corresponds to mean TRF length, we studied with fibroblast cell culture, which was obtained from simply passaged culture in our laboratory. The confocal laser scanning microscopy showed decrease in signal intensity with increasing population doubling levels (PDLs) (Fig. 1A). Autoradiograph showed decrease in TRF length with increasing PDLs (Fig. 1B). After calibration of background to zero on the confocal images, total intensity of telomere signals in the area of each nucleus represented as sum of intensities of pixels (Table 1). There were significant diffence in the size of scan area, i.e. nuclear size dropped onto glass slides, among PDL 3, 20, 35 and $50(P<0.001$, ANOVA test). Except for PDL 50, however, multiple comparisons did not show significant differences in the size of scan area between groups of PDL 3, 20 and 35. Sum of intensities were also significantly different and decrease with increasing PDLs $(P<0.001$, ANOVA test and $P<0.05$, multiple comparisons between any pairs). Mean TRF lengths also decreased with increasing PDLs.

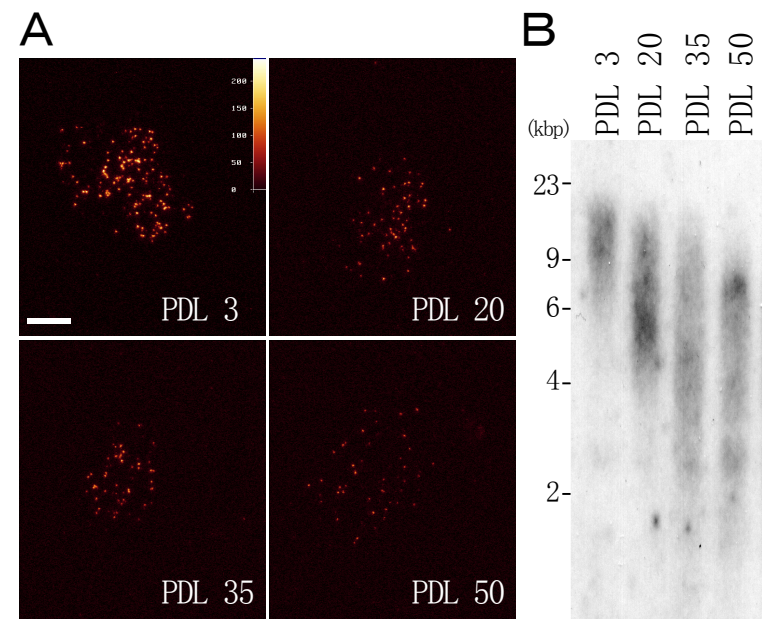

Figure 1. Loss of telomeric DNA in cultured human fibroblasts. (A) Confocal laser scanning microscopy images of telomere fluorescent signals in interphase nucleus dropped on to glass slides. Scale bar, 10 $\mu m$. (B) Telomere-specific Southern blot.

Table 1. Intensities of confocal image and mean TRF length

\begin{tabular}{lllll}
\hline PDL & $\mathbf{n}$ & $\begin{array}{l}\text { Size of scan area* } \\
\left(\boldsymbol{\mu \mathbf { m } ^ { 2 } )}\right.\end{array}$ & Sum of intensities** & $\begin{array}{l}\text { Mean TRF } \\
\text { length (bp) }\end{array}$ \\
\hline 3 & 45 & $616 \pm 145$ & $267,356 \pm 73,624$ & 8,971 \\
20 & 35 & $519 \pm 126$ & $225,807 \pm 36,777$ & 6,209 \\
35 & 35 & $439 \pm 245$ & $188,607 \pm 48,506$ & 4,419 \\
50 & 29 & $3,738 \pm 1,163$ & $85,077 \pm 44,073$ & 4,079 \\
\hline
\end{tabular}

*Area size to enclose each nucleus

**Sum of intensities of all pixels composing scan area

\subsection{Changes in Telomere Size with Keratinization}

Changes in TRF length were investigated in trypsin-isolated keratinocytes. After $15 \mathrm{~min}$ of trypsin treatment of skin samples from the back, keratin 10 (K10)-positive suprabasal cells in the epidermal sheets decreased in thickness with time (Fig. 2Aa-Ad). Immunostaining of released cell fractions showed gradual increases in K10-positive cells with time from $21 \%$ during the first $5 \mathrm{~min}$ to $83 \%$ after the final trypsin treatment (Fig. 2Bi-Bk). Simultaneously, K5-positive cells were detached from the bottom of epidermal sheets (Fig. 2Ae-Ah), 
confirming K5-positive cells in the liberated cell fractions (Fig. 2Bl-Bn). Compared to K10 staining (Fig. 2Aa), K5 staining could not quantitate the proportions of basal cells in each fraction, since K5 was not only stained in the basal layer, but also weakly stained in the parabasal layer (Fig. 2Ae). After $15 \mathrm{~min}$ of trypsin treatment, most viable cells were released, and only keratinized, i.e., dead, cells in the stratum corneum remained (Fig. 2Ad, Ah).

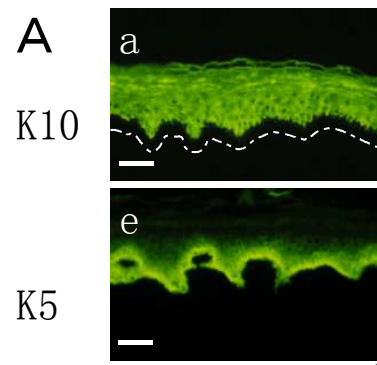

0 min

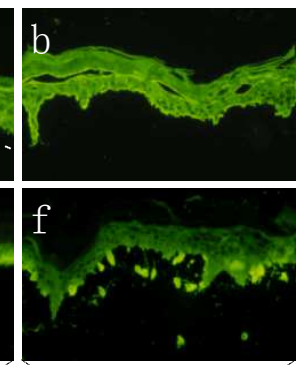

$5 \mathrm{~min}$

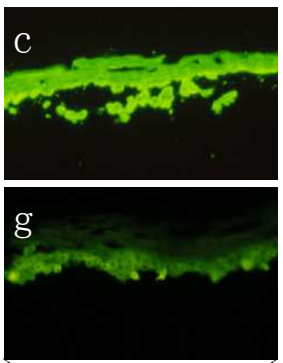

$10 \min$

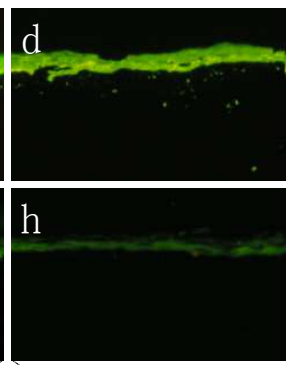

$15 \min$

$\mathrm{B}$

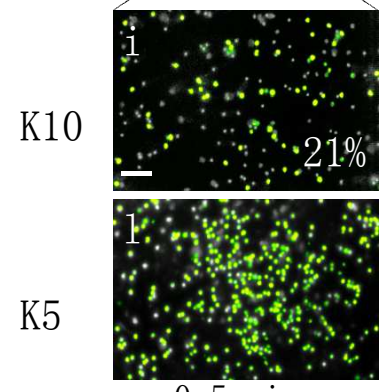

$0-5$ min

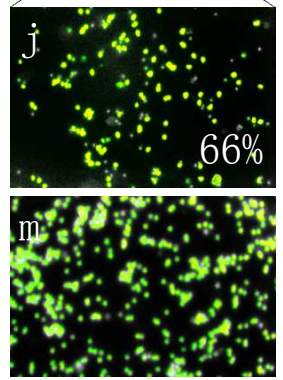

$5-10 \mathrm{~min}$

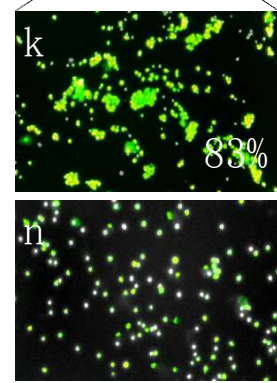

$10-15 \mathrm{~min}$

Figure 2. Trypsinized time-dependent fractionation of keratinocytes in human back skin. (A) Frozen sections of epidermis. Epidermis became thinner from the basal layer to the corneal layer with increasing trypsin treatment time. K10 was strongly stained in the suprabasal layer, but not in the basal layer (a-d). Dotted line indicates basement membrane (a). (B) Keratinocytes from epidermis. Color merged images of fluorescence of K10/K5 staining (green) and DAPI (gray). The proportion of K10-stained cells increased with trypsin treatment time (i-k), but K5-stained cells showed the opposite trend (l-n). Proportions were determined from stained cell count by total nuclear counts stained with DAPI. Scale bar, $100 \mu m$.

A

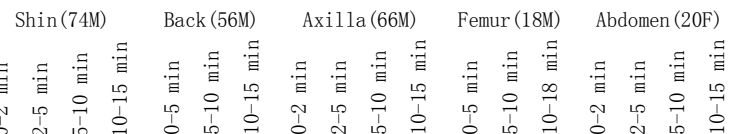

(kbp)

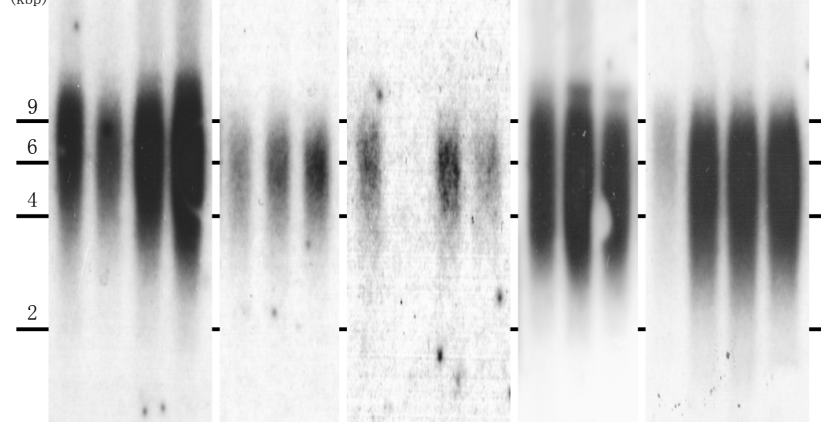

B

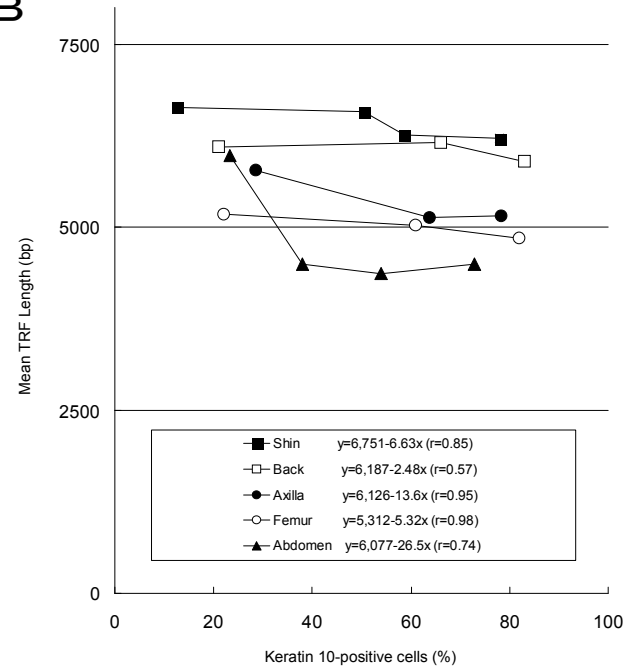

Figure 3. Quantitative relationships between mean TRF length in trypsin-fractionated keratinocytes and K10 positivity at five body sites. (A) Telomere-specific Southern blot. Bands shifted to the lower molecular weight from the basal cell-rich fraction to the suprabasal cell-rich fraction. The 2-5 min lane from axilla was null because of DNA extraction failure. (B) Mean TRF lengths were plotted against the proportion of K10-positive cells in each fraction. All sights showed decreasing mean TRF length with differentiated keratinocytes becoming dominant. $y=$ telomere length $(\mathrm{bp}) ; x=$ proportion of K10-positive cells (\%). 
Fig. 3A shows Southern blot analysis of TRFs in the isolated cell fractions from the epidermis, demonstrating that bands shifted to the lower molecular weight group from the initial basal cell-rich fraction to the intermediate and final keratinized cell-rich fractions. This was quantitatively demonstrated in Table 2 and Fig. 3B. Epidermis obtained from various sites of the body, such as the back, abdomen, axilla and legs, showed shortening of mean TRF length from $5,932 \pm 470$ (range $5,182-6,630$ ) bp in the first fraction to $5,320 \pm 640$ (range 4,495-6,212) bp in the final fraction $(\mathrm{n}=$ 5). The decrease in mean TRF length was statistically significant $(P=0.027$, paired t-test). On simple linear regression, extrapolation of the mean TRF length to the vertical axis in Fig. 3B showed 6,091 \pm 513 (range 5,312-6,751) bp at $0 \% \mathrm{~K} 10$-positivity and 5,000 $\pm 1,077$ (range 3,427-6,088) bp at 100\% K10-positivity. The loss of mean TRF length between basal cells and keratinized cells were therefore $1,091 \pm 963$ (range 248-2,650) bp.

Table 2. Mean TRF length and keratin 10-positivity in each fraction

\begin{tabular}{lllll}
\hline & 1st & 2nd & 3rd & 4th \\
\hline \multirow{2}{*}{ Shin } & $6,630^{*}$ & 6,576 & 6,263 & 6,212 \\
& $(12.6)^{* *}$ & $(50.4)$ & $(58.6)$ & $(78.0)$ \\
Back & 6,100 & 6,150 & 5,889 & \\
& $(21.0)$ & $(66.0)$ & $(83.0)$ & \\
Axilla & 5,775 & 5,132 & 5,154 & \\
& $(28.6)$ & $(63.7)$ & $(78.2)$ & \\
Femur & 5,182 & 5,023 & 4,852 & \\
& $(22.0)$ & $(61.0)$ & $(82.0)$ & \\
Abdomen & 5,973 & 4,495 & 4,365 & 4,495 \\
& $(23.3)$ & $(38.0)$ & $(53.9)$ & $(72.8)$ \\
\hline
\end{tabular}

*Upper row: mean TRF length (bp).

**Parentheses: keratin 10-positivity of the fraction (\%).

\subsection{Topographic Variation in Intensity of Telomere Fluorescence Signals}

Skin samples from the sole and forehead were analyzed by FISH and telomeres showed strong fluorescence in all nuclei in skin sections. In each of the 30 serial skin sections, we found occasionally distinguishable clusters of epidermal cells from the surrounding epidermal cells as an indicator of one very bright signal in their nuclei in both skin samples (Fig. 4A-D). The epidermal cells with regularity of the fluorescence intensity made columnar distribution from the basal layer through the granular layer. The isolated groups of cells appeared in neighboring serial skin sections and revealed that they compose neither acrosyringium nor hair follicle. To confirm that they have different length of telomere from surrounding epidermal cells, basal cells were consecutively numbered from left to right for further quantitative analysis (Fig. 4C, D). Group of keratinocytes numbered 12-24 in Fig. $4 \mathrm{C}$ correspond to area from the tip of the dermal papilla (DP) to the bottom of the rete ridge (RR). Cells numbered 11-19 in Fig. 4D correspond to area from the tip of DP to the bottom of RR, and cells numbered 20-31 correspond to areas from the bottom of RR to the tip of DP. Maximal fluorescence intensity in each basal nucleus recorded by confocal microscopy showed histographic distribution in each cell, as shown in Fig. 5 . Fluorescence intensity was plotted on numbered basal cells corresponding to the numbers in Fig. 4. Cell groups were divided with subsidiary lines by the tip of DP and the bottom of RR. Each cell group divided by subsidiary lines contained 10-15 basal cells. In the skin samples obtained from different body sites, the groups of epidermal cells with one very long telomere in each nucleus, i.e. cells numbered 12-24 in Fig. 4C and $5 \mathrm{~A}$, and numbered $11-19$ in Fig. $4 \mathrm{D}$ and 5B, had statistically significant different length of telomere compared to the groups of epidermal cells in the vicinity (Fig. 5).

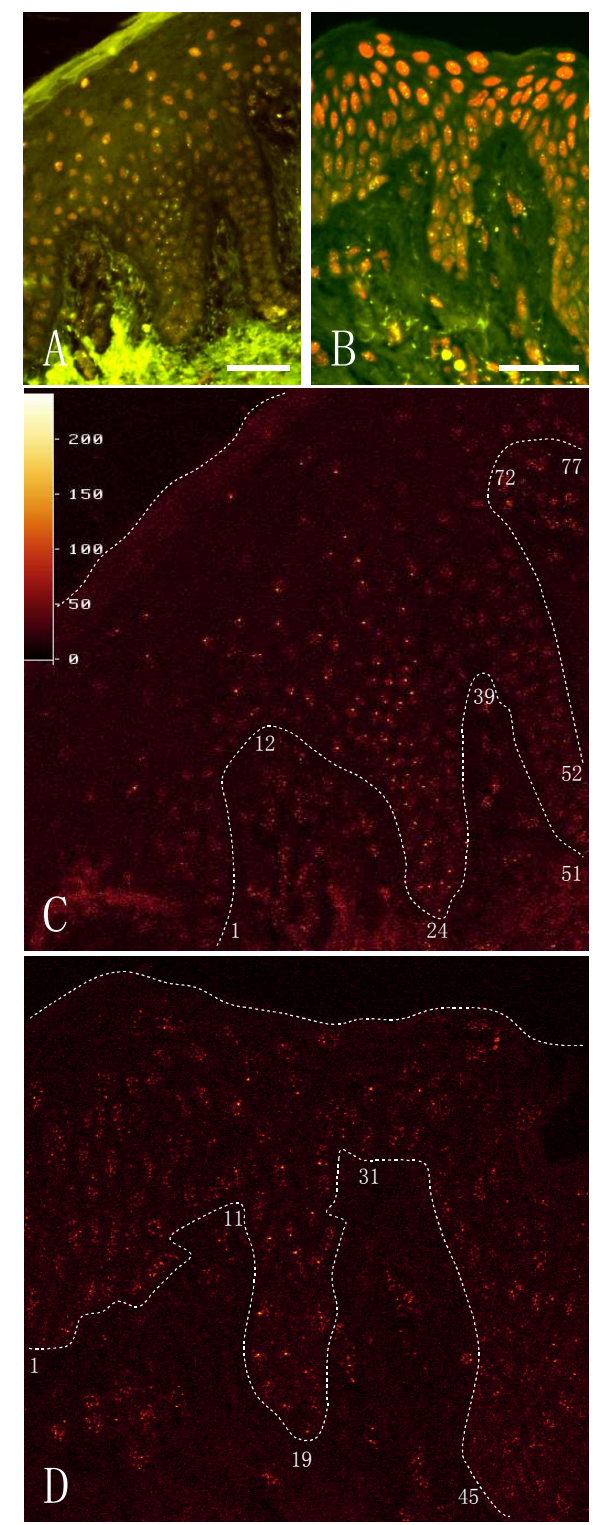

Figure 4. Semi-quantitative FISH using digoxigenin-labeled telomere probes in normal skin sections. Fluorescence micrographs $(A, B)$ and confocal images $(C, D)$. Dotted lines enclose epidermis. Skin samples from sole $(A, C)$ and forehead $(B, D)$ occasionally showed columnar groups of keratinocytes, sectioned from the top of $D P$ or the bottom of $R R$, with one bright signal in each nucleus. Numbers correspond to each basal cell. Scale bar, $100 \mu \mathrm{m}$. 

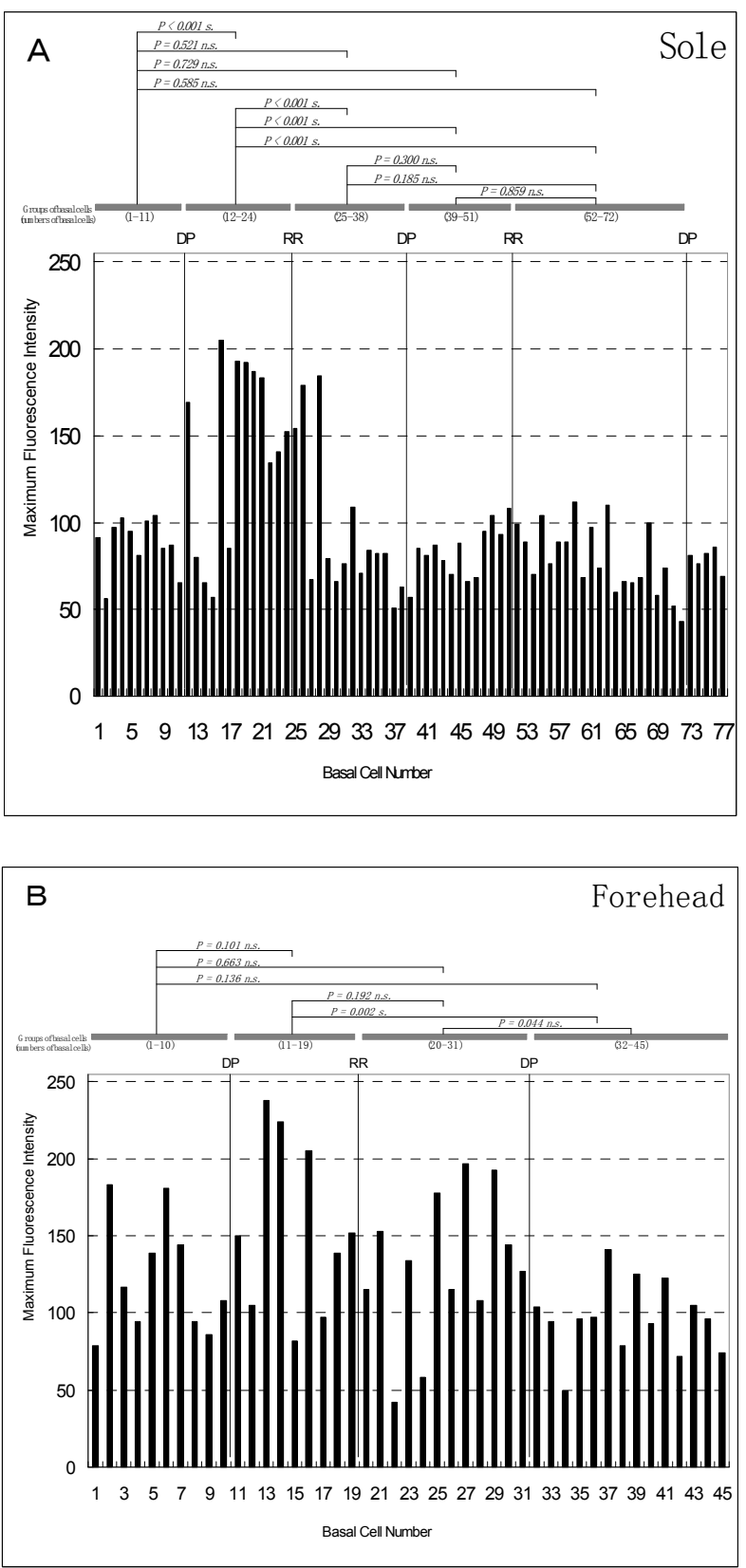

Figure 5. Maximum fluorescence intensity in each basal cell. Horizontal axis indicates cell number corresponding to numbers in Fig. 4. Vertical axis indicates intensity. Statistical differences between groups, sectioned by bottom of RR and tip of DP were measured by ANOVA test and following multiple comparisons. (A) "Sole" shows the five sectioned groups of basal cells. There were significant differences in intensities among the five groups $(P<0.001$, ANOVA test). Following multiple comparisons showed significant differences between group of cell numbered 12-24 and any other groups of cells. (B) Similarly, "Forehead" shows the four sectioned groups of cells. There were significant differences in intensities among the four groups $(P=0.018$, ANOVA test). Following multiple comparisons showed significant differences between groups of cell numbered 11-19 and 32-45 (P $=0.002$ ). s.: significant, n.s.: not significant.

\section{Discussion}

The present study used a time-dependent trypsin isolation method to separate the epidermis into three or four fractions and demonstrated that telomeres in suprabasal cells were shorter when compared with basal cells by Southern blotting methods. Quantification by densitometric analysis allowed us to calculate mean TRF length of basal keratinocytes as 6,091 $\pm 513 \mathrm{bp}$, and that of fully keratinized cells as 5,000 $\pm 1,077$ bp. This implies that suprabasal cells have 1,091 $\pm 963 \mathrm{bp}$ shorter telomeres compared to basal cells. Shortening in telomere size in similar stratified epithelial tissues in different layers has previously been investigated by FISH analysis in lingual epithelium [19] and esophagus [20], showing that parabasal cells have shortened telomeres.

Although our study showed the shorter telomere length in suprabasal layer than in basal layer, further study may be required, since the Southern blot analysis has limitation of resolution [21]. The previous studies of age-dependent telomere shortening [10-15] had been compensated by handling large number of samples and the calculated gradual telomere shortening per year.

The telomere shortening in basal and suprabasal cells requires several factors to be taken into consideration; the ratio of dividing basal cells in basal layer, the number of divisions of replicating basal cells before leaving the basement membrane, and the pace of telomere shortening per cell division. Cell culture studies in human epidermal keratinocytes by Miyata et al. showed that TRF lengths shortened 628-1,589 bp during population doubling level (PDL) 35 by the feeder layer method, and 685-1,484 bp during PDL 48 by serum-free culture [22]; thus, telomeres shorten by tens of bp per cell division in vitro. Telomere loss is typically explained as resulting from incomplete DNA replication ("end replication problem"), and the processing of chromosome ends following replication [5]. On the other, DNA damaging agents, such as reactive oxygen species, ultraviolet and chemicals could be a major cause of telomere shortening in human cells [5,23]. On FISH analysis, Ikeda et al. showed that telomeres in sun-exposed skin were shorter than those in sun-protected skin [24]. Krunic et al. compared mean telomere lengths among basal, suprabasal and upper layers by the FISH method, and found that telomere lengths were very similar among those layers in 10 of 14 samples in their experiments [14].

In addition, the present study demonstrated topographic variations in telomere length by FISH in normal skin sections. After provisionally subdividing the epidermis into sections at the bottom of RR and the tip of DP, comparisons of maximal fluorescence intensity of telomere signals between groups of basal cells showed heterogeneous clusters of keratinocytes forming epidermis. No previous studies analyzing telomere length by FISH analysis have addressed the differences among groups of keratinocytes. The validity of our sectioning of epidermis at the bottom of RR and the tip of DP for comparisons is based on a study by Jones et al. [25]. They showed that basal cells were different between the bottom of RR and the tip of DP in expression of $\alpha 2 \beta 1$ and $\alpha 3 \beta 1$ integrin levels and colony forming potential in vitro; the bottom of RR and/or the tip of DP are one of the dividing points of epidermis.

The present study raises a question about why groups of 
keratinocytes with one very long telomere in each nucleus occasionally and independently exist in the epidermis. The modified end-replication problem, based on the 3'-overhanged DNA end structure, predicts that leading ends become shorter and lagging ends avoid telomere shortening during DNA replication [26]. As more cells divide, preserved telomeres would become less in frequency, but more conspicuous in length. We postulated that the reason for significant differences in telomere length among cell groups was as follows: 1) CPCs may give rise to daughter cells for comparatively long periods, leading to variations in telomere length between cell groups; and 2) CPCs derived from distinct SCs may be arranged side-by-side.

\section{Conclusion}

The present study showed that the telomere lengths of suprabasal cells were shorter than those of basal cells by Southern blotting method. In addition, by using FISH method, we showed some groups of epidermal cells having different length of telomeres compared to the other epidermal cells in the vicinity. The changes and variation in telomere length in the epidermal cells would be related to the organization of the basal layer and various factors affecting telomere length regulations.

\section{Acknowledgements}

The author is grateful to Dr. Titia de Lange (Laboratory of Cell Biology and Genetics, Rockefeller University) for providing plasmid pTH5, and Dr. Yutaka Hozumi (Department of Dermatology, University of Yamagata) for isolation and culture of fibroblasts from human skin samples.

\section{References}

[1] Blackburn EH. Structure and function of telomeres. Nature 1991; 350: 569-73.

[2] Zakian VA. Telomeres: beginning to understand the end. Science 1995; 270: 1601-7.

[3] Moyzis RK, Buckingham JM, Cram LS, Dani M, Deaven LL, Jones MD, Meyne J, Ratliff RL, Wu JR. A highly conserved repetitive DNA sequence, (TTAGGG)n, present at the telomeres of human chromosomes. Proc Natl Acad Sci U S A. 1988; 85: 6622-6.

[4] Harley CB. "Telomeres and aging." in Telomeres, Blackburn EH, Greider CW, Eds. Cold Spring Harbor Laboratory Press, 1995, pp. 247-63.

[5] Aubert G, Lansdorp PM. Telomeres and aging. Physiol Rev 2008; 88: 557-79.

[6] Blanpain C, Fuchs E. Epidermal homeostasis: a balancing act of stem cells in the skin. Nat Rev Mol Cell Biol. 2009; 10: 207-17.

[7] Clayton E, Doupé DP, Klein AM, Winton DJ, Simons BD, Jones PH. A single type of progenitor cell maintains normal epidermis. Nature 2007; 446: 185-9.

[8] Mascré G, Dekoninck S, Drogat B, Youssef KK, Broheé S, Sotiropoulou PA, Simons BD, Blanpain C. Distinct contribution of stem and progenitor cells to epidermal maintenance. Nature 2012; 489: 257-62.

[9] de Rosa L, de Luca M. Cell biology: Dormant and restless skin stem cells. Nature 2012; 489: 215-7.

[10] Lindsey J, McGill NI, Lindsey LA, Green DK, Cooke HJ. In vivo loss of telomeric repeats with age in humans. Mutat Res. 1991; 256: 45-8.

[11] Friedrich U, Griese E, Schwab M, Fritz P, Thon K, Klotz U. Telomere length in different tissues of elderly patients. Mech Ageing Dev. 2000; 119: 89-99.

[12] Nakamura K, Izumiyama-Shimomura N, Sawabe M, Arai T, Aoyagi Y, Fujiwara M, Tsuchiya E, Kobayashi Y, Kato M, Oshimura M, Sasajima K, Nakachi K, Takubo K. Comparative analysis of telomere lengths and erosion with age in human epidermis and lingual epithelium. J Invest Dermatol. 2002; 119: 1014-9.

[13] Sugimoto M, Yamashita R, Ueda M. Telomere length of the skin in association with chronological aging and photoaging. J Dermatol Sci. 2006; 43: 43-7.

[14] Krunic D, Moshir S, Greulich-Bode KM, Figueroa R, Cerezo A, Stammer H, Stark HJ, Gray SG, Nielsen KV, Hartschuh W, Boukamp P. Tissue context-activated telomerase in human epidermis correlates with little age-dependent telomere loss. Biochim Biophys Acta. 2009; 1792: 297-308.

[15] Ishikawa N, Nakamura K, Izumiyama-Shimomura N, Aida J, Ishii A, Goto $\mathrm{M}$, Ishikawa $\mathrm{Y}$, Asaka $\mathrm{R}$, Matsuura $\mathrm{M}$, Hatamochi A, Kuroiwa M, Takubo K. Accelerated in vivo epidermal telomere loss in Werner syndrome. Aging (Albany NY). 2011; 3: 417-29.

[16] Härle-Bachor C, Boukamp P. Telomerase activity in the regenerative basal layer of the epidermis in human skin and in immortal and carcinoma-derived skin keratinocytes. Proc Natl Acad Sci U S A. 1996; 93: 6476-81.

[17] Bryant JE, Hutchings KG, Moyzis RK, Griffith JK. Measurement of telomeric DNA content in human tissues. Biotechniques. 1997; 23: 476-8.

[18] de Lange T, Shiue L, Myers RM, Cox DR, Naylor SL, Killery AM, Varmus HE. Structure and variability of human chromosome ends. Mol Cell Biol. 1990; 10: 518-27.

[19] Aida J, Izumiyama-Shimomura N, Nakamura K, Ishikawa N, Poon SS, Kammori M, Sawabe M, Arai T, Matsuura M, Fujiwara M, Kishimoto H, Takubo K. Basal cells have longest telomeres measured by tissue Q-FISH method in lingual epithelium. Exp Gerontol. 2008; 43: 833-9.

[20] Takubo K, Fujita M, Izumiyama N, Nakamura K, Ishikawa N, Poon SS, Fujiwara M, Sawabe M, Matsuura M, Grabsch H, Arai T, Aida J. Q-FISH analysis of telomere and chromosome instability in the oesophagus with and without squamous cell carcinoma in situ. J Pathol. 2010; 221: 201-9.

[21] Montpetit AJ, Alhareeri AA, Montpetit M, Starkweather AR, Elmore LW, Filler K, Mohanraj L, Burton CW, Menzies VS, Lyon DE, Jackson-Cook CK. Telomere length: a review of methods for measurement. Nurs Res. 2014; 63: 289-99. 
[22] Miyata Y, Okada K, Fujimoto A, Hata K, Kagami H, Tomita $\mathrm{Y}$, Ueda $\mathrm{M}$. The effect of the long-term cultivation on telomere length and morphology of cultured epidermis. J Dermatol Sci. 2004; 34: 221-30.

[23] Buckingham EM, Klingelhutz AJ. The role of telomeres in the ageing of human skin. Exp Dermatol. 2011; 20: 297-302.

[24] Ikeda H, Aida J, Hatamochi A, Hamasaki Y, Izumiyama-Shimomura N, Nakamura K, Ishikawa N, Poon SS, Fujiwara M, Tomita K, Hiraishi N, Kuroiwa M, Matsuura M, Sanada Y, Kawano Y, Arai T, Takubo K. Quantitative fluorescence in situ hybridization measurement of telomere length in skin with/without sun exposure or actinic keratosis. Hum Pathol. 2014; 45: 473-80.

[25] Jones PH, Harper S, Watt FM. Stem cell patterning and fate in human epidermis. Cell. 1995; 80: 83-93.

[26] Wellinger RJ. In the end, what's the problem? Mol Cell. 2014; 53: 855-6. 